\title{
Channeling chaotic transport in a wave-particle experiment
}

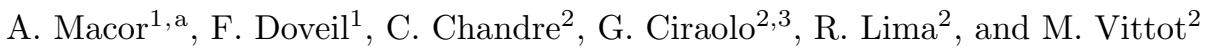 \\ 1 Équipe turbulence plasma, PIIM, CNRS/Université de Provence, Centre Saint-Jérôme, case 321, 13397 Marseille, France \\ 2 Centre de Physique Théorique, CNRS, Luminy, case 907, 13288 Marseille, France \\ 3 Association Euratom-CEA, DRFC/DSM/CEA, CEA Cadarache, 13108 St. Paul-lez-Durance, France
}

Received 27 April 2007

Published online 29 June 2007 - (c) EDP Sciences, Società Italiana di Fisica, Springer-Verlag 2007

Eur. Phys. J. D 41, 519-530 (2007)

Replace $s=0.85$ by $s=1.05$ both in the caption of Figure 9 and in Section 3.2. The values of $C_{h} \Phi$ and $C_{b} \Phi$ in Section 3.2 correspond to $s=1.27$.

\footnotetext{
${ }^{a}$ e-mail: macor@up.univ-mrs.fr
} 